\title{
Discovery of an Allosteric, Inactive-conformation Selective Inhibitor of Full-length HPK1 Utilizing a Kinase Cascade Assay
}

\section{Supporting Information}

Weixue Wang ${ }^{l}$, Laurence Mevellec ${ }^{2}$, Annie Liul ${ }^{l}$, Geoff Strublel, Robyn Miller ${ }^{l}$, Samantha J.

Allen ${ }^{1}$, Kelly Federowicz' ${ }^{1}$ Berthold Wroblowski ${ }^{3}$, Jorge Vialard ${ }^{4}$, Kay Ahn ${ }^{1}$, and Daniel

Krosky $^{1 *}$

${ }^{1}$ Discovery Technologies and Molecular Pharmacology, Janssen Research and Development,

Spring House, PA 19477, USA. ${ }^{2}$ Discovery Chemistry, Janssen Research and Development, Val

de Reuil, France. ${ }^{3}$ Computational Chemistry and ${ }^{4}$ Oncology Discovery Biology, Janssen

Research and Development, Beerse, Belgium. 


\section{Contents}

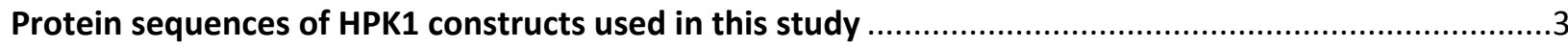

Figure S1. Size exclusion chromatogram of purified unphosphorylated inactive full-length HPK1 ............6

Figure S2. HPK1 activation in the presence or absence of proposed upstream kinases ...........................7

Figure S3. Autophosphorylation of HPK1 occurs through an intermolecular mechanism .........................8

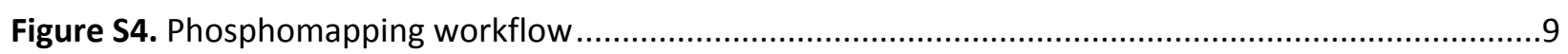

Figure S5. Reaction progress curve of inactive HPK1 cascade assay under the HTS assay condition ........10

Figure S6. Dose-response curves of 1 against ITK, LCK, ZAP70.......................................................11

Figure S7. Compound 1 inhibits the ATPase activity of HPK1 in a cascade assay...................................12

Figure S8. Assessing binding of $\mathbf{1}$ to full-length and truncated HPK1 by differential scanning fluorimetry

Figure S9. Limited trypsinolysis of unphosphorylated, full-length HPK1. ............................................14

Table S1. Steady state velocities of wildtype and mutant HPK1 preparations.......................................16

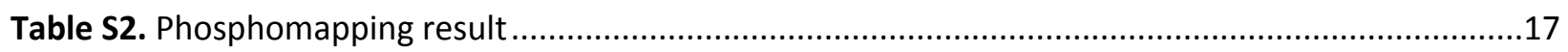

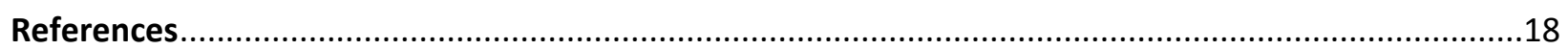


Protein sequences of HPK1 constructs used in this study

Full-length wild-type HPK1:

$>\mathrm{HPK}_{1} \mathrm{His}_{6}$

MDVVDPDIFNRDPRDHYDLLQRLGGGTYGEVFKARDKVSGDLVALKMVKMEPDDDVSTLQKEILILKTCRHANIVAYH GSYLWLQKLWICMEFCGAGSLQDIYQVTGSLSELQISYVCREVLQGLAYLHSQKKIHRDIKGANILINDAGEVRLADFGIS AQIGATLARRLSFIGTPYWMAPEVAAVALKGGYNELCDIWSLGITAIELAELQPPLFDVHPLRVLFLMTKSGYQPPRLKE KGKWSAAFHNFIKVTLTKSPKKRPSATKMLSHQLVSQPGLNRGLILDLLDKLKNPGKGPSIGDIEDEEPELPPAIPRRIRST HRSSSLGIPDADCCRRHMEFRKLRGMETRPPANTARLQPPRDLRSSSPRKQLSESSDDDYDDVDIPTPAEDTPPPLPPKP KFRSPSDEGPGSMGDDGQLSPGVLVRCASGPPPNSPRPGPPPSTSSPHLTAHSEPSLWNPPSRELDKPPLLPPKKEKMK RKGCALLVKLFNGCPLRIHSTAAWTHPSTKDQHLLLGAEEGIFILNRNDQEATLEMLFPSRTTWVYSINNVLMSLSGKTP HLYSHSILGLLERKETRAGNPIAHISPHRLLARKNMVSTKIQDTKGCRACCVAEGASSGGPFLCGALETSVVLLQWYQPM NKFLLVRQVLFPLPTPLSVFALLTGPGSELPAVCIGVSPGRPGKSVLFHTVRFGALSCWLGEMSTEHRGPVQVTQVEED MVMVLMDGSVKLVTPEGSPVRGLRTPEIPMTEAVEAVAMVGGQLQAFWKHGVQVWALGSDQLLQELRDPTLTFRL LGSPRPVVVETRPVDDPTAPSNLYIQEENLYFQGHHHHHH

> HPK1_FLAG_His 10

MDVVDPDIFNRDPRDHYDLLQRLGGGTYGEVFKARDKVSGDLVALKMVKMEPDDDVSTLQKEILILKTCRHANIVAYH GSYLWLQKLWICMEFCGAGSLQDIYQVTGSLSELQISYVCREVLQGLAYLHSQKKIHRDIKGANILINDAGEVRLADFGIS AQIGATLARRLSFIGTPYWMAPEVAAVALKGGYNELCDIWSLGITAIELAELQPPLFDVHPLRVLFLMTKSGYQPPRLKE KGKWSAAFHNFIKVTLTKSPKKRPSATKMLSHQLVSQPGLNRGLILDLLDKLKNPGKGPSIGDIEDEEPELPPAIPRRIRST HRSSSLGIPDADCCRRHMEFRKLRGMETRPPANTARLQPPRDLRSSSPRKQLSESSDDDYDDVDIPTPAEDTPPPLPPKP KFRSPSDEGPGSMGDDGQLSPGVLVRCASGPPPNSPRPGPPPSTSSPHLTAHSEPSLWNPPSRELDKPPLLPPKKEKMK RKGCALLVKLFNGCPLRIHSTAAWTHPSTKDQHLLLGAEEGIFILNRNDQEATLEMLFPSRTTWVYSINNVLMSLSGKTP HLYSHSILGLLERKETRAGNPIAHISPHRLLARKNMVSTKIQDTKGCRACCVAEGASSGGPFLCGALETSVVLLQWYQPM NKFLLVRQVLFPLPTPLSVFALLTGPGSELPAVCIGVSPGRPGKSVLFHTVRFGALSCWLGEMSTEHRGPVQVTQVEED MVMVLMDGSVKLVTPEGSPVRGLRTPEIPMTEAVEAVAMVGGQLQAFWKHGVQVWALGSDQLLQELRDPTLTFRL LGSPRPVVVETRPVDDPTAPSNLYIQEGGDYKDDDDKHHHHHHHHHH

\section{HPK1 T165A mutant}

>HPK1_T165A_His 6

MDVVDPDIFNRDPRDHYDLLQRLGGGTYGEVFKARDKVSGDLVALKMVKMEPDDDVSTLQKEILILKTCRHANIVAYH GSYLWLQKLWICMEFCGAGSLQDIYQVTGSLSELQISYVCREVLQGLAYLHSQKKIHRDIKGANILINDAGEVRLADFGIS AQIGAALARRLSFIGTPYWMAPEVAAVALKGGYNELCDIWSLGITAIELAELQPPLFDVHPLRVLFLMTKSGYQPPRLKE KGKWSAAFHNFIKVTLTKSPKKRPSATKMLSHQLVSQPGLNRGLILDLLDKLKNPGKGPSIGDIEDEEPELPPAIPRRIRST HRSSSLGIPDADCCRRHMEFRKLRGMETRPPANTARLQPPRDLRSSSPRKQLSESSDDDYDDVDIPTPAEDTPPPLPPKP KFRSPSDEGPGSMGDDGQLSPGVLVRCASGPPPNSPRPGPPPSTSSPHLTAHSEPSLWNPPSRELDKPPLLPPKKEKMK RKGCALLVKLFNGCPLRIHSTAAWTHPSTKDQHLLLGAEEGIFILNRNDQEATLEMLFPSRTTWVYSINNVLMSLSGKTP HLYSHSILGLLERKETRAGNPIAHISPHRLLARKNMVSTKIQDTKGCRACCVAEGASSGGPFLCGALETSVVLLQWYQPM NKFLLVRQVLFPLPTPLSVFALLTGPGSELPAVCIGVSPGRPGKSVLFHTVRFGALSCWLGEMSTEHRGPVQVTQVEED MVMVLMDGSVKLVTPEGSPVRGLRTPEIPMTEAVEAVAMVGGQLQAFWKHGVQVWALGSDQLLQELRDPTLTFRL LGSPRPVVVETRPVDDPTAPSNLYIQEENLYFQGHHHHHH 


\section{HPK1 S171A mutant}

>HPK1_S171A_His

MDVVDPDIFNRDPRDHYDLLQRLGGGTYGEVFKARDKVSGDLVALKMVKMEPDDDVSTLQKEILILKTCRHANIVAYH GSYLWLQKLWICMEFCGAGSLQDIYQVTGSLSELQISYVCREVLQGLAYLHSQKKIHRDIKGANILINDAGEVRLADFGIS AQIGATLARRLAFIGTPYWMAPEVAAVALKGGYNELCDIWSLGITAIELAELQPPLFDVHPLRVLFLMTKSGYQPPRLKE KGKWSAAFHNFIKVTLTKSPKKRPSATKMLSHQLVSQPGLNRGLILDLLDKLKNPGKGPSIGDIEDEEPELPPAIPRRIRST HRSSSLGIPDADCCRRHMEFRKLRGMETRPPANTARLQPPRDLRSSSPRKQLSESSDDDYDDVDIPTPAEDTPPPLPPKP KFRSPSDEGPGSMGDDGQLSPGVLVRCASGPPPNSPRPGPPPSTSSPHLTAHSEPSLWNPPSRELDKPPLLPPKKEKMK RKGCALLVKLFNGCPLRIHSTAAWTHPSTKDQHLLLGAEEGIFILNRNDQEATLEMLFPSRTTWVYSINNVLMSLSGKTP HLYSHSILGLLERKETRAGNPIAHISPHRLLARKNMVSTKIQDTKGCRACCVAEGASSGGPFLCGALETSVVLLQWYQPM NKFLLVRQVLFPLPTPLSVFALLTGPGSELPAVCIGVSPGRPGKSVLFHTVRFGALSCWLGEMSTEHRGPVQVTQVEED MVMVLMDGSVKLVTPEGSPVRGLRTPEIPMTEAVEAVAMVGGQLQAFWKHGVQVWALGSDQLLQELRDPTLTFRL LGSPRPVVVETRPVDDPTAPSNLYIQEENLYFQGHHHHHH

\section{HPK1 T165A/S171A double mutant}

>HPK1_T165A_S171A_His 6

MDVVDPDIFNRDPRDHYDLLQRLGGGTYGEVFKARDKVSGDLVALKMVKMEPDDDVSTLQKEILILKTCRHANIVAYH GSYLWLQKLWICMEFCGAGSLQDIYQVTGSLSELQISYVCREVLQGLAYLHSQKKIHRDIKGANILINDAGEVRLADFGIS AQIGAALARRLAFIGTPYWMAPEVAAVALKGGYNELCDIWSLGITAIELAELQPPLFDVHPLRVLFLMTKSGYQPPRLKE KGKWSAAFHNFIKVTLTKSPKKRPSATKMLSHQLVSQPGLNRGLILDLLDKLKNPGKGPSIGDIEDEEPELPPAIPRRIRST HRSSSLGIPDADCCRRHMEFRKLRGMETRPPANTARLQPPRDLRSSSPRKQLSESSDDDYDDVDIPTPAEDTPPPLPPKP KFRSPSDEGPGSMGDDGQLSPGVLVRCASGPPPNSPRPGPPPSTSSPHLTAHSEPSLWNPPSRELDKPPLLPPKKEKMK RKGCALLVKLFNGCPLRIHSTAAWTHPSTKDQHLLLGAEEGIFILNRNDQEATLEMLFPSRTTWVYSINNVLMSLSGKTP HLYSHSILGLLERKETRAGNPIAHISPHRLLARKNMVSTKIQDTKGCRACCVAEGASSGGPFLCGALETSVVLLQWYQPM NKFLLVRQVLFPLPTPLSVFALLTGPGSELPAVCIGVSPGRPGKSVLFHTVRFGALSCWLGEMSTEHRGPVQVTQVEED MVMVLMDGSVKLVTPEGSPVRGLRTPEIPMTEAVEAVAMVGGQLQAFWKHGVQVWALGSDQLLQELRDPTLTFRL LGSPRPVVVETRPVDDPTAPSNLYIQEENLYFQGHHHHHH

\section{HPK1 1-297 (kinase domain)}

>HPK1_kinase_domain

GAMDVVDPDIFNRDPRDHYDLLQRLGGGTYGEVFKARDKVSGDLVALKMVKMEPDDDVSTLQKEILILKTCRHANIVA YHGSYLWLQKLWICMEFCGAGSLQDIYQVTGSLSELQISYVCREVLQGLAYLHSQKKIHRDIKGANILINDAGEVRLADF GISAQIGAALARRLAFIGTPYWMAPEVAAVALKGGYNELCDIWSLGITAIELAELQPPLFDVHPLRVLFLMTKSGYQPPR LKEKGKWSAAFHNFIKVTLTKSPKKRPSATKMLSHQLVSQPGLNRGLILDLLDKLKNPGKG

HPK1 T165A residues 1-467 (kinase domain + part of the proline-rich linker, with T165A mutation) >HPK1_T165A_1-467_His

MDVVDPDIFNRDPRDHYDLLQRLGGGTYGEVFKARDKVSGDLVALKMVKMEPDDDVSTLQKEILILKTCRHANIVAYH GSYLWLQKLWICMEFCGAGSLQDIYQVTGSLSELQISYVCREVLQGLAYLHSQKKIHRDIKGANILINDAGEVRLADFGIS AQIGAALARRLSFIGTPYWMAPEVAAVALKGGYNELCDIWSLGITAIELAELQPPLFDVHPLRVLFLMTKSGYQPPRLKE KGKWSAAFHNFIKVTLTKSPKKRPSATKMLSHQLVSQPGLNRGLILDLLDKLKNPGKGPSIGDIEDEEPELPPAIPRRIRST 
HRSSSLGIPDADCCRRHMEFRKLRGMETRPPANTARLQPPRDLRSSSPRKQLSESSDDDYDDVDIPTPAEDTPPPLPPKP KFRSPSDEGPGSMGDDGQLSPGVLVRCASGPPPNSPRPGPPPSTSSPHLTAHSEPSLWNPPSRELDGHHHHHH

HPK1 residues 295-821 (proline-rich linker + Citron homology domain)

>HPK1_295-821_His

MGKGPSIGDIEDEEPELPPAIPRRIRSTHRSSSLGIPDADCCRRHMEFRKLRGMETRPPANTARLQPPRDLRSSSPRKQLS ESSDDDYDDVDIPTPAEDTPPPLPPKPKFRSPSDEGPGSMGDDGQLSPGVLVRCASGPPPNSPRPGPPPSTSSPHLTAH SEPSLWNPPSRELDKPPLLPPKKEKMKRKGCALLVKLFNGCPLRIHSTAAWTHPSTKDQHLLLGAEEGIFILNRNDQEAT LEMLFPSRTTWVYSINNVLMSLSGKTPHLYSHSILGLLERKETRAGNPIAHISPHRLLARKNMVSTKIQDTKGCRACCVAE GASSGGPFLCGALETSVVLLQWYQPMNKFLLVRQVLFPLPTPLSVFALLTGPGSELPAVCIGVSPGRPGKSVLFHTVRFG ALSCWLGEMSTEHRGPVQVTQVEEDMVMVLMDGSVKLVTPEGSPVRGLRTPEIPMTEAVEAVAMVGGQLQAFWK HGVQVWALGSDQLLQELRDPTLTFRLLGSPRPVVVETRPVDDPTAPSNLYIQEGHHНHНHНH 


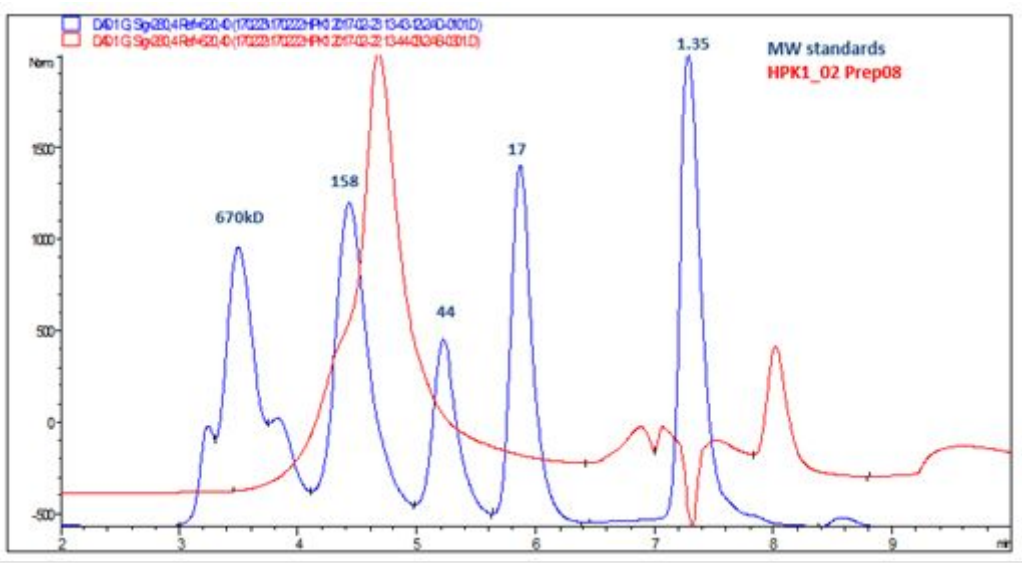

Figure S1. Size exclusion chromatogram of purified unphosphorylated inactive full-length HPK1. Red trace, chromatogram of HPK1. Blue trace, molecular weight standards. 


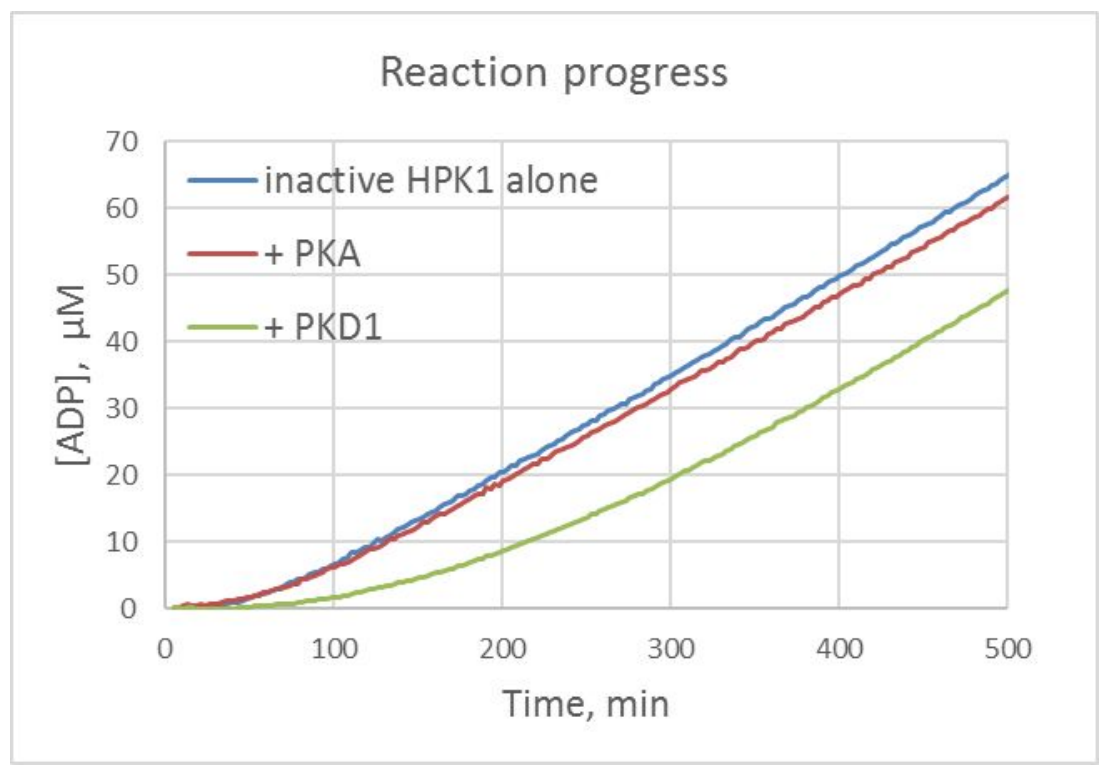

Figure S2. HPK1 activation in the presence or absence of proposed upstream kinases, including PKA (red trace) and PKD1 (green trace). The blue trace is HPK1 activation in the absence of any upstream kinase. Protein substrates were not included, and ATPase activities were monitored by PK/LDH assay. 


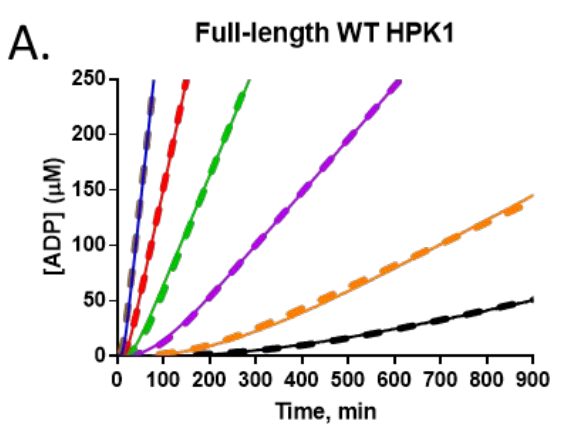

C.

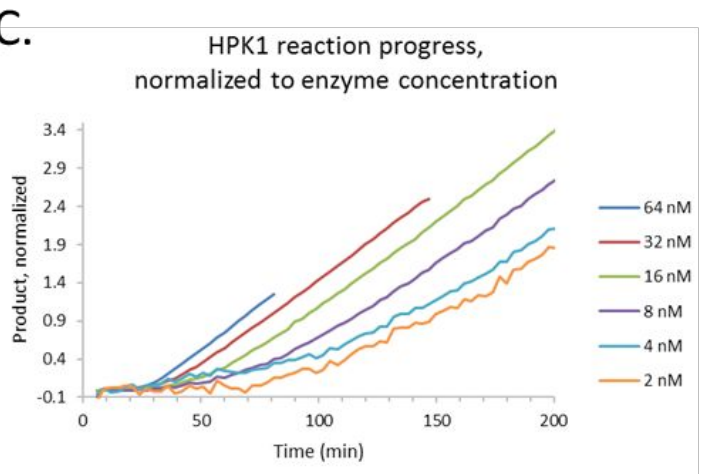

$$
\begin{aligned}
& -0.1 \mu \mathrm{M} \\
& -0.05 \mu \mathrm{M} \\
& -0.025 \mu \mathrm{M} \\
& -0.0125 \mu \mathrm{M} \\
& -0.00625 \mu \mathrm{M} \\
& -0.003125 \mu \mathrm{M}
\end{aligned}
$$

Full-length WT HPK1, data fit to

B. activation by upstream kinase model

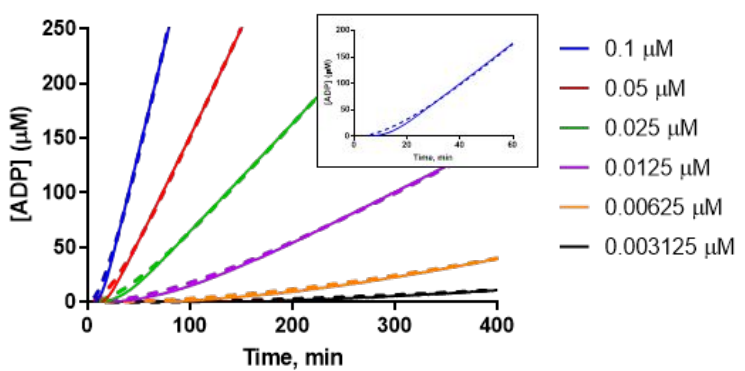

D.

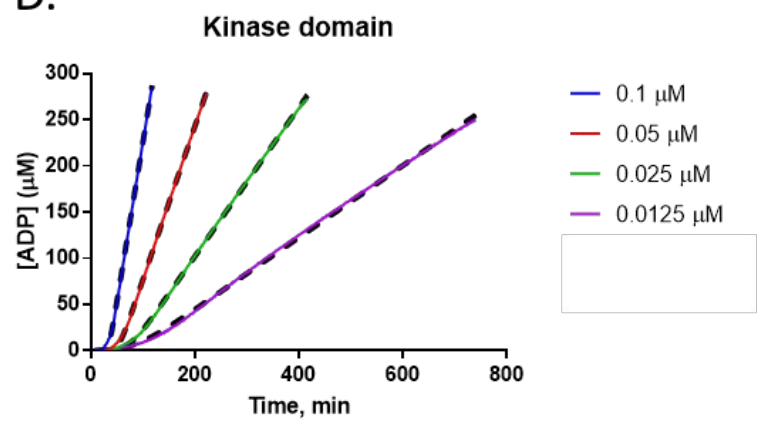

Figure S3. Autophosphorylation of HPK1 occurs through an intermolecular mechanism. (A) Autophosphorylation of wild-type full-length HPK1 at varying HPK1 concentrations fit well to an intermolecular autophosphorylation model. ${ }^{1}$ (B) Autophosphorylation of wild-type full-length HPK1 does not fit well to the model that describes activation by an upstream kinase. ${ }^{1}$ For clarity, the inset shows the fit to the $0.1 \mu \mathrm{M}$ HPK1 data, which highlights the differences in the activation phase between the measured data and the upstream kinase activation model (C) Reaction progress curves normalized to enzyme concentrations do not overlay, suggesting intermolecular autophosphorylation. ${ }^{2}$ (D) Autophosphorylation of HPK1 kinase domain protein fit well to an intermolecular autophosphorylation model. ${ }^{1}$ Solid traces are experimental data and dashed lines the fitted curves. 


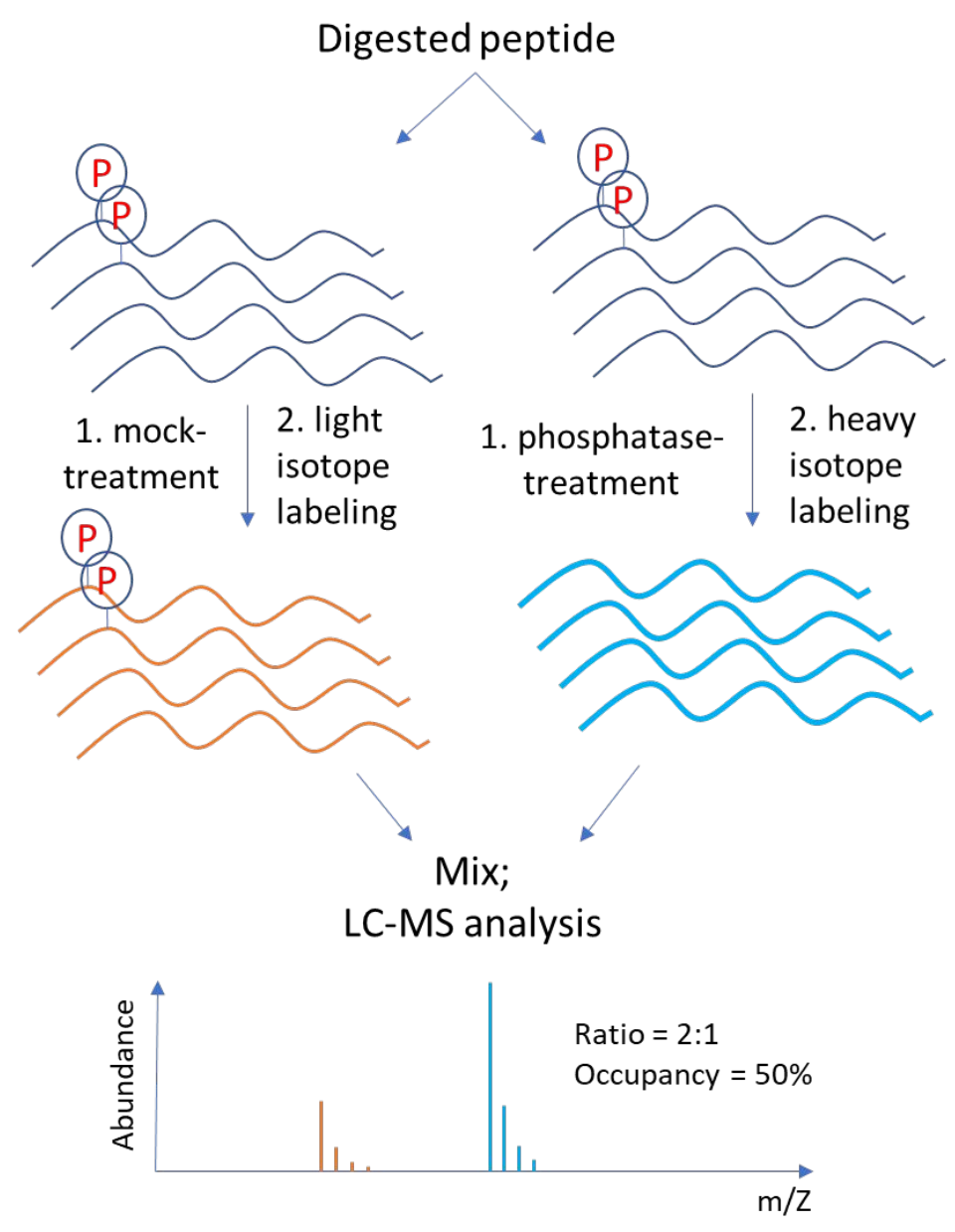

Figure S4. Phosphomapping workflow, adopted from reference 3. Each sample was digested and split into two identical aliquots. One aliquot was treated with protein phosphatase and the other mocktreated. The two aliquots were then labeled with stable isotopes (e.g., phosphatase-treated sample was labeled with heavy isotope-mTRAQ and mock-treated sample with light isotope-mTRAQ) and were mixed together. The mixed samples were analyzed by liquid chromatography-mass spectrometry. For each unphosphorylated peptide detected, the ratio of heavy and light isotope-labeled peptide was quantified and occupancy of phosphorylation at each site in the original sample was calculated. 


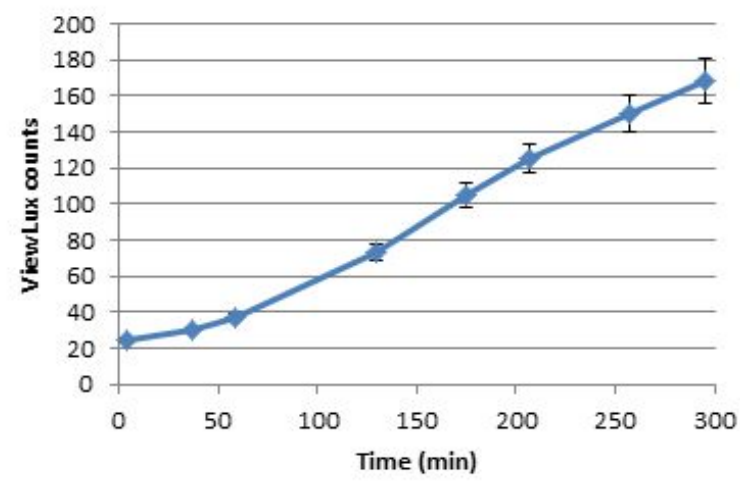

Figure S5. Reaction progress curve of inactive HPK1 cascade assay under the HTS assay condition.

Reactions were performed in a 1536-well plate (Corning catalog number 3725), $4 \mu \mathrm{L} /$ well, and contained $2 \mathrm{nM}$ HPK1, $10 \mu \mathrm{M}$ ATP, $0.04 \mathrm{Ci} / \mathrm{L}\left[\gamma^{-33} \mathrm{P}\right]$-ATP and $0.8 \mu \mathrm{M}$ biotinylated SLP-76. Reactions were quenched at each time point by adding $4 \mu \mathrm{L} /$ well quenching solution containing $40 \mathrm{mM}$ EDTA, $0.001 \%$ Tween-20 and $4 \mathrm{mg} / \mathrm{mL}$ SPA beads in phosphate buffered saline. The plate was read using a Viewlux plate imager (PerkinElmer). 


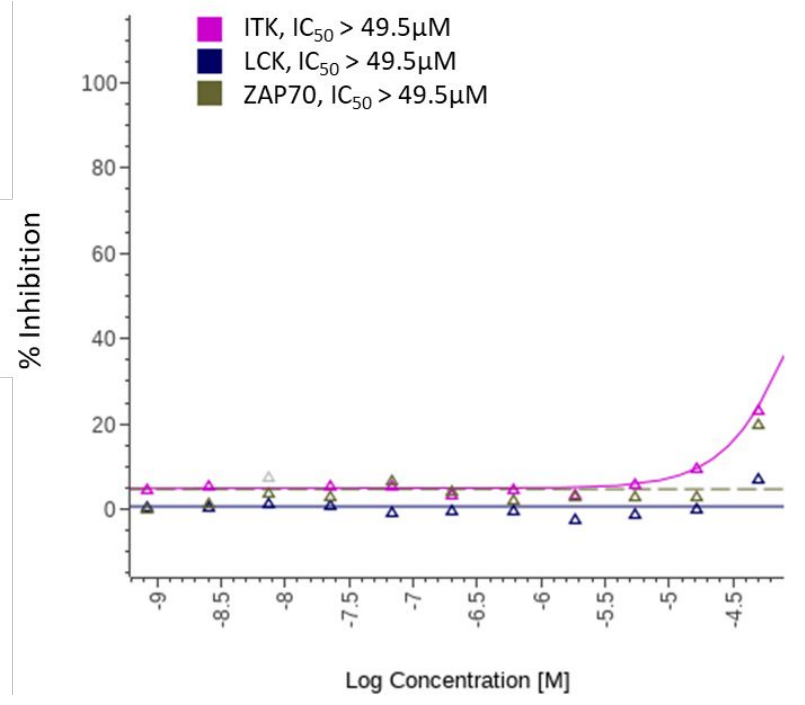

Figure S6. Dose-response curves of 1 against ITK, LCK, ZAP70. 
ADP Glo, with or without SLP-76

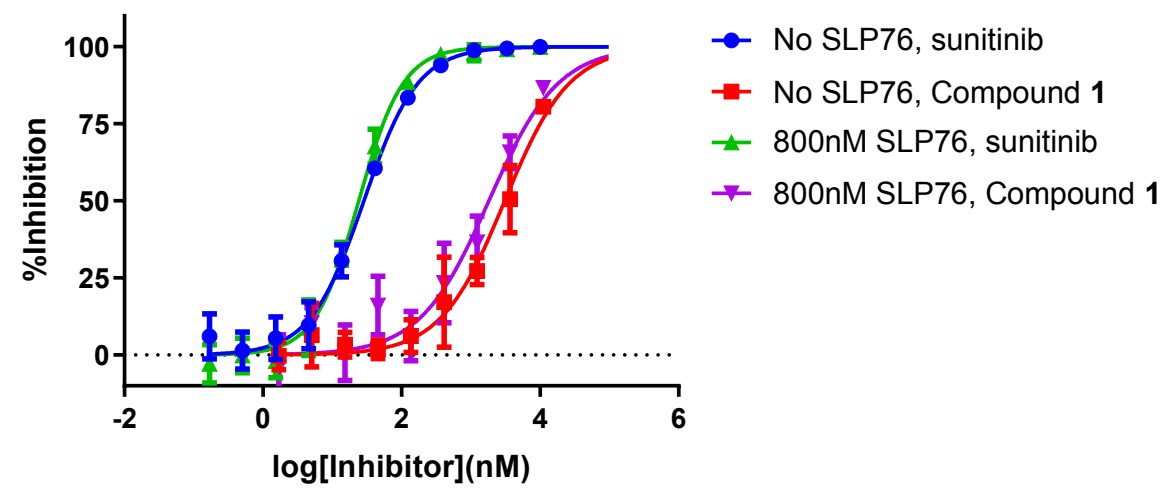

Figure S7. Compound $\mathbf{1}$ inhibited the ATPase activity of HPK1 in a cascade assay. IC $\mathrm{C}_{50}$ values of $\mathbf{1}$ and the control compound sunitinib were measured in the presence or absence of the protein substrate SLP-76, and ADP production was measured by ADP Glo assay. The results indicated that 1 had IC $C_{50}$ values of 3.1 $\mu \mathrm{M}$ and $1.8 \mu \mathrm{M}$ in the absence and presence of SLP-76, respectively. The $\mathrm{IC}_{50}$ values of sunitinib was 28.6 $\mathrm{nM}$ and $24.1 \mathrm{nM}$ in the absence and presence of SLP-76, respectively. 
A
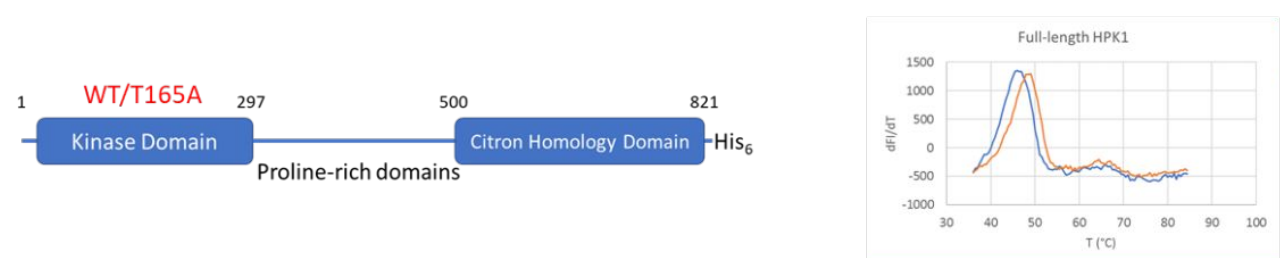

Compound A

- DMSO

$\Delta T_{\mathrm{M}}=1.5^{\circ} \mathrm{C}$

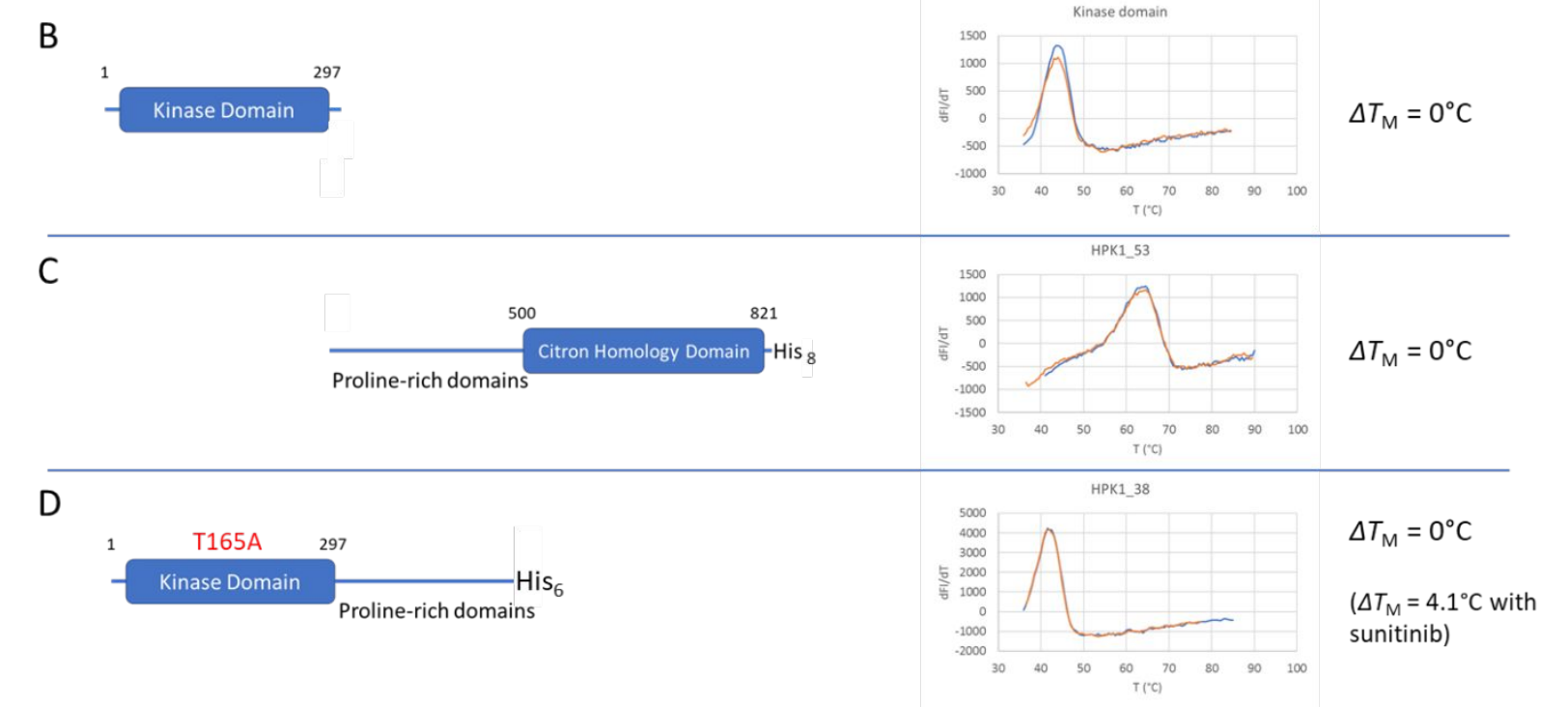

Kinase domain

Figure S8. Assessing binding of 1 to full-length and truncated HPK1 by differential scanning fluorimetry. (A) $33 \mu \mathrm{M} 1$ shifted the $\mathrm{T}_{\mathrm{M}}$ value of unphosphorylated, full-length HPK1 by $1.5^{\circ} \mathrm{C}$. (B) HPK1 kinase domain, (C) truncated HPK1 without the kinase domain, or (D) truncated HPK1 without the Citron homology domain and part of the linker exhibited no measurable $T_{M}$ shift in the presence of 1 . 
A.

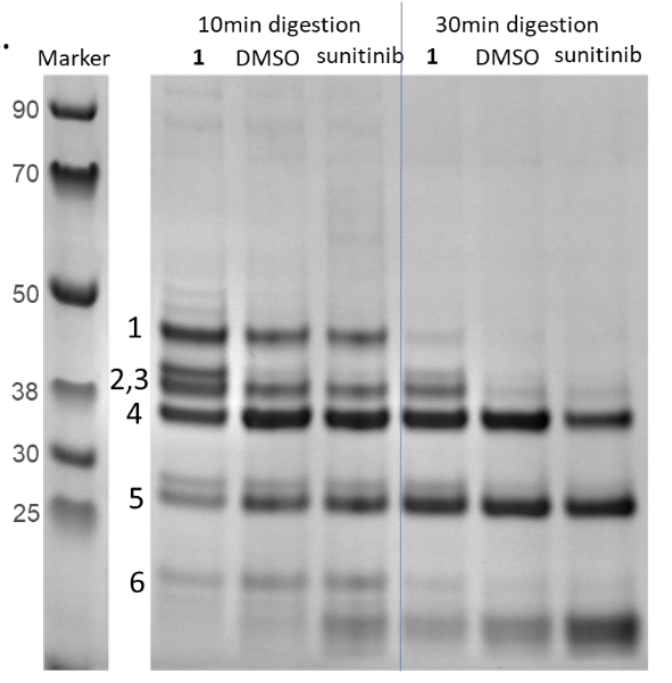

B.

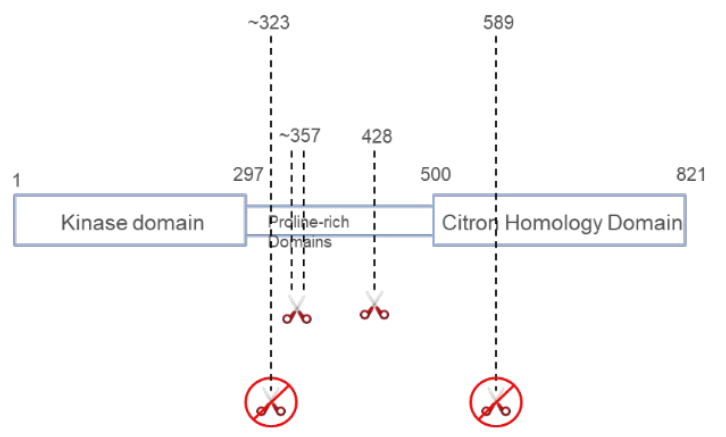

Figure S9. Limited trypsinolysis of unphosphorylated, full-length HPK1. (A) SDS-PAGE analysis of limited HPK1 trypsinolysis products in the presence of $\mathbf{1}$, sunitinib, or DMSO. Trypsinolysis reactions were quenched at $10 \mathrm{~min}$ or $30 \mathrm{~min}$. (B) Schematic representation of the digestion sites in the linker and in the Citron homology domain protected by 1.

The result showed that Compound $\mathbf{1}$ was able to protect a site on the Citron homology domain, as well as a site on the proline-rich domain near its putative interface with the kinase domain relative to both a DMSO vehicle control and the ATP-competitive inhibitor sunitinib. As shown in Figure S9A, 10min after limited trypsinolysis, bands 1-3 were more intense in the presence of 1, whereas bands 4-6 exhibited decreased intensity. Identities of these bands were determined by $\mathrm{N}$-terminal peptide sequencing. Band 1 corresponds to a peptide that starts with residues CASGP at its $\mathrm{N}$-terminus, indicating that it is the product of trypsin digestion between residues 427 and 428 . It includes part of the proline-rich domain and the entire Citron homology domain. The theoretical molecular weight of this peptide is $44.6 \mathrm{kDa}$, consistent with estimation using molecular weight marker on the gel. Peptides at band 5 and 6 are the products of digestion of the peptide at band 1 , as band 6 has the same $\mathrm{N}$-terminal sequence as band 1 , and band 5 starts with residues LLAR, indicating a digestion site between residues 589 and 590, within the Citron homology domain. The theoretical molecular weight of these two fragments, $26.7 \mathrm{kDa}$ and $17.9 \mathrm{kDa}$, are consistent with estimations using molecular markers on the gel. Compared with DMSO vehicle control and sunitinib control, the higher intensity of band 1 and lower intensity of its digestion products band 5 and 6 indicate that Compound 1 protected the digestion site between residue 589 and 590 , within the citron homology domain.

Peptides at bands 2-4 did not react with Edman reagent due to blocked N-terminus. ${ }^{4}$ Although no Nterminal sequence information was obtained for these peptides, the fact that they are $\mathrm{N}$-terminal blocked suggests that they are fragments that has the $\mathrm{N}$-terminus of the full-length HPK1, the starting material of this experiment. Band 4 is likely the product of digestion of band 2 and 3 , as in the presence of compound 1, intensities of band 2 and 3 decreased upon extended incubation to 30 min, whereas the intensity of band 4 increased. Molecular weight estimation using molecular weight makers on the gel suggests that these peptides correspond to HPK1 residues 1 to approx. 323 (band 4) and 1 to approx. 357 (band 2,3). Because multiple possible trypsin digestion sites are present around residues 323 and 
357 and the molecular weight estimations are not accurate, we cannot pin-point the trypsin digestion sites, but these peptides clearly indicate digestion sites in the proline-rich domain. In the presence of $\mathbf{1}$, the weaker intensity of band 4 and the stronger intensities of its presumed parent fragments at band 2 and 3 suggest protection of a digestion site at or near residue 323 when 1 binds to HPK1. 
Table S1. Steady state velocities of wild-type and mutant HPK1 preparations. Reaction velocities measured by PK/LDH assay for 40nM enzyme with 100 $\mu \mathrm{M}$ ATP were calculated for wild-type and mutant HPK1 preparations (reaction progress curves are shown in Figure 2B). For the wild-type preparation, data between 700 and 800 min were used for the calculation. For mutant preparations, data between 860 and $960 \mathrm{~min}$ were used.

\begin{tabular}{|c|c|c|c|c|}
\hline HPK1 preparation & Wildtype & T165A & S171A & T165A/S171A \\
\hline $\begin{array}{l}\text { Reaction velocities } \\
(\triangle \mathrm{Abs} \text { orbance }(340 \mathrm{~nm}) / \text { hour })\end{array}$ & 0.0588 & 0.0345 & 0.0074 & 0.00089 \\
\hline
\end{tabular}


Table S2. Phosphomapping result.

\begin{tabular}{|c|c|c|c|c|c|c|}
\hline Sequence & $\begin{array}{c}\text { selected } \\
\text { detected } \\
\text { phosphorylation } \\
\text { sites }\end{array}$ & $\begin{array}{l}\text { HPK1+LCK+ATP } \\
\text { (\% occupancy) }\end{array}$ & $\begin{array}{l}\text { HPK1+PKA+ATP } \\
\text { (\% occupancy) }\end{array}$ & $\begin{array}{c}\text { HPK1+ATP } \\
(\% \\
\text { occupancy) }\end{array}$ & $\begin{array}{c}\text { Inactive } \\
\text { HPK1 } \\
\text { (\% } \\
\text { occupancy) }\end{array}$ & \begin{tabular}{|c|} 
as- \\
purified \\
HPK1 \\
$(\%$ \\
occupancy)
\end{tabular} \\
\hline MDVVDPDIFNRDPRDHYDLLQR & Y17 & 10.2 & 0.0 & 2.0 & 0.0 & 0.0 \\
\hline LGGGTYGEVFK & T27/Y28 & 15.8 & 11.9 & 6.9 & 0.0 & 0.0 \\
\hline ARDKVSGDLVALK & S39 & 0.0 & 13.3 & 0.0 & 0.0 & 0.0 \\
\hline MVKMEPDDDVSTLQK & S57/T58 & 0.1 & 0.0 & 6.4 & 0.0 & 0.0 \\
\hline MEPDDDVSTLQKEILILK & S57/T58 & 55.6 & 61.2 & 79.8 & 0.0 & 6.8 \\
\hline HANIVAYHGSYLWLQK & $\mathrm{S} 80 / \mathrm{Y} 81$ & 32.5 & 0.0 & 0.0 & 0.0 & 2.0 \\
\hline EVLQGLAYLHSQK & $\mathrm{Y} 127 / \mathrm{S} 130$ & 0.0 & 0.0 & 0.0 & 0.0 & 0.0 \\
\hline LADFGISAQIGATLAR & S159/T165 & 83.2 & 77.2 & 78.2 & 0.0 & 0.0 \\
\hline RLSFIGTPYWMAPEVAAVALK & S171/T175/Y177 & 93.2 & 93.5 & 93.2 & 0.0 & 17.9 \\
\hline MLSHQLVSQPGLNR & $S 270 / S 275$ & 0.0 & 0.0 & 0.2 & 15.9 & 0.0 \\
\hline GPSIGDIEDEEPELPPAIPR & S299 & 0.0 & 0.0 & 1.0 & 0.0 & 0.0 \\
\hline SSSLGIPDADCCRR & S324/S326 & 77.7 & 81.2 & 79.3 & 8.9 & 0.0 \\
\hline LRGMETRPPANTAR & Т349/Т355 & 62.2 & 66.7 & 65.2 & 7.2 & 0.7 \\
\hline KQLSESSDDDYDDVDIPTPAEDTPPPL & $\begin{array}{l}\text { S374/377/378, } \\
\text { KY381, Т388/393 }\end{array}$ & 46.0 & 26.6 & 27.6 & 0.0 & 0.4 \\
\hline FRSPSDEGPGSMGDDGQLSPGVLVR & $S 407 / S 413 / S 421$ & 52.1 & 62.5 & 63.3 & 4.7 & 16.7 \\
\hline PGPPPSTSSPHLTAHSEPSLWNPPSR & $\mathrm{T} 445 / \mathrm{T} 451$ & $\mathrm{NaN}$ & 85.5 & 91.4 & 9.4 & 8.4 \\
\hline IHSTAAWTHPSTK & T501/T505 & 1.7 & 2.0 & 1.3 & 11.0 & 0.0 \\
\hline NDQEATLEMLFPSR & T533 & 0.0 & 0.0 & 0.0 & 9.1 & 0.0 \\
\hline ITWWYSINNVLMSLSGK & Y546/S547/S554 & 0.0 & 0.0 & 3.3 & 8.7 & 0.0 \\
\hline TPHLYSHSILGLLER & Y563/S564/S566 & 0.0 & 0.6 & 3.2 & 1.2 & 0.0 \\
\hline FGALSCWLGEMSTEHR & S697 & 27.9 & 28.2 & 29.2 & 14.0 & 0.0 \\
\hline GPVQVTQVEEDMVMVLMDGSVK & $S 728$ & 0.6 & 0.0 & 0.0 & 0.0 & 0.3 \\
\hline HGVQVWALGSDQLLQELRDPTLTFR & T791 & 0.0 & 2.8 & 3.4 & 5.9 & 0.0 \\
\hline LLGSPRPVVVETR & S797/T805 & 0.0 & 0.0 & 3.9 & 11.7 & 6.9 \\
\hline
\end{tabular}




\section{References}

(1) Wang, W.; Krosky, D.; Ahn, K. (2017) Discovery of Inactive Conformation-Selective Kinase Inhibitors by Utilizing Cascade Assays, Biochemistry 56, 4449-4456.

(2) Dodson, C. A.; Yeoh, S.; Haq, T.; Bayliss, R. (2013) A kinetic test characterizes kinase intramolecular and intermolecular autophosphorylation mechanisms, Sci Signal 6, ra54.

(3) Wu, R.; Haas, W.; Dephoure, N.; Huttlin, E. L.; Zhai, B.; Sowa, M. E.; Gygi, S. P. (2011) A large-scale method to measure absolute protein phosphorylation stoichiometries, Nat. Methods 8, 677-683.

(4) Wellner, D.; Panneerselvam, C.; Horecker, B. L. (1990) Sequencing of peptides and proteins with blocked N-terminal amino acids: $\mathrm{N}$-acetylserine or $\mathrm{N}$-acetylthreonine, Proc. Natl. Acad. Sci. U. S. A. 87, 1947-1949. 